\title{
Quality of Life in Peritoneal Carcinomatosis: A Prospective Study in Patients Undergoing Cytoreductive Surgery and Hyperthermic Intraperitoneal Chemotherapy (HIPEC)
}

\author{
Markus Albertsmeier ${ }^{\mathrm{a}}$ Alexandra Hauer ${ }^{\mathrm{a}}$ Hanno Niess $^{\mathrm{a}}$ Jens Werner ${ }^{\mathrm{a}}$ \\ Christian Graeb ${ }^{\mathrm{b}}$ Martin K. Angele ${ }^{\mathrm{a}}$ \\ a Department of General, Visceral, Transplantation, Vascular and Thoracic Surgery, Ludwig Maximilians University,

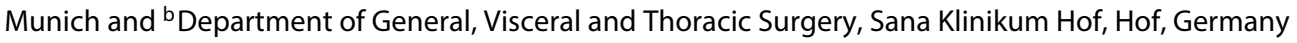

\section{Key Words}

Peritoneal neoplasms · Quality of life · Cytoreductive surgery

\begin{abstract}
Background/Aims: Cytoreductive surgery and hyperthermic intraperitoneal chemoperfusion (HIPEC) can improve survival in selected patients with peritoneal carcinomatosis, but bear a significant risk of perioperative morbidity. The aim of this study was to prospectively evaluate the quality of life (QoL) following cytoreduction and HIPEC. Methods: In this study including 40 patients ( $65 \%$ females) with different primary tumors, the EORTC QLQ-C30 questionnaire was applied prior to CS and HIPEC as well as 3, 9, and 18 months postoperatively. Results: Global health status was not impaired significantly following HIPEC. Scales and symptom scores that deteriorated 3 months postoperatively $(p<0.05)$, that is, physical, role, and social functions as well as fatigue, pain, dyspnea, insomnia, and diarrhea, all returned to preoperative values within 9 months. Conclusions: Following cytoreductive surgery and HIPEC, QoL returns to preoperative levels within 9 months. Selected patients that are likely to benefit oncologically from HIPEC should not be denied this option for fear of reduced postoperative QoL.
\end{abstract}

C.G. and M.K.A. contributed equally to this work.

Prof. Dr. med. Martin K. Angele

Ludwig Maximilians University, Grosshadern Campus

Department of General, Visceral, Transplantation, Vascular and Thoracic Surgery

Marchioninistr. 15, DE-81377 Munich (Germany)

E-Mail Martin.Angele@med.uni-muenchen.de

In patients with abdominal malignancies, the occurrence of peritoneal carcinomatosis is associated with a significantly reduced life expectancy and quality of life. Survival correlates well with the extent of the disease at initial diagnosis: for patients with non-gynecologic malignancies, life expectancy drops from 9.8 months if only nodules of less than $5 \mathrm{~mm}$ are seen on a single spot to 3.7 months if nodules larger than $2 \mathrm{~cm}$ are present [1]. In addition, large tumor masses are frequently complicated by intestinal or urinary obstruction [2] with a substantial impact on the quality of life of these patients.

Treatment of peritoneal carcinomatosis is, in most cases, limited to palliative measures. Palliative chemotherapy has been shown to increase survival [3], but cure is rarely achieved. In this respect, cytoreductive surgery followed by hyperthermic intraperitoneal chemoperfusion (HIPEC) has become a therapeutic option with curative intent for patients with limited disease. In addition to the primary peritoneal tumors pseudomyxoma peritonei and malignant peritoneal mesothelioma, it can be offered to suitable patients with limited peritoneal carcinomato- 
sis (as defined by Verwaal et al. [4]) due to colorectal carcinoma, mucinous appendix carcinoma, and, sometimes, gastric cancer and recurrent ovarian cancer. It has been shown that cytoreductive surgery followed by HIPEC improves survival in selected patients with colorectal carcinoma [4].

Cytoreductive surgery aims to resect all tumor nodules larger than $2.5 \mathrm{~mm}$ and HIPEC is used to treat any residual microscopic disease. The advantage of HIPEC lies in the high concentration of hydrophilic chemotherapeutic agents that can be achieved locally with low plasma concentrations compared to systemic application [5].

The procedure, however, bears a significant risk of morbidity and mortality [6-9]. In a study of 67 patients by Schmidt et al., the overall morbidity amounted to $34 \%$ [10] and the extent of surgery turned out to be the main contributing factor. Hence, the potential survival benefit must be weighed against a possible loss in quality of life associated with the procedure and its complications.

Previous retrospective studies described an acceptable or good quality of life after HIPEC [10-12], but no prospective evaluation had been published when we started the present study. We, therefore, aimed to prospectively evaluate the health-related quality of life in peritoneal cancer patients undergoing cytoreduction and HIPEC. The primary question was whether the quality of life after cytoreductive surgery and HIPEC would return to preoperative levels and if so when.

\section{Patients and Methods}

\section{Study Design and Participants}

This study was designed as an analysis of prospectively collected quality-of-life data in patients undergoing cytoreductive surgery and HIPEC. The quality-of-life assessment was routinely conducted for all patients receiving cytoreductive surgery and HIPEC at our department during the study period. Inclusion and exclusion criteria were therefore the same as for HIPEC and are detailed in table 1 . For the present analysis, all patients with at least 3 months of follow-up during the study period were identified.

At the beginning of the surgical procedure, the entire abdomen was routinely explored to assess the extent of peritoneal carcinomatosis. For objective assessment, the Peritoneal Cancer Index (PCI) according to Sugarbaker et al. was calculated [13]. Cytoreductive surgery is generally deemed feasible if the PCI is 20 or smaller, which was one of our inclusion criteria, evaluated on preoperative CT scans. In nine patients, intraoperative exploration of the abdomen revealed a PCI larger than 20 . The procedure was nonetheless continued in these patients because the surgeon judged it to be feasible taking into account the involvement of abdominal regions according to Verwaal et al. [4].

Quality of Life Following Cytoreductive Surgery and HIPEC
Table 1. Inclusion and exclusion criteria for HIPEC

Inclusion criteria:

- Age $>18$ years and $<70$ years

- Limited peritoneal carcinomatosis: PCI $<20$ on preoperative CT scan

- Tumor entity suitable for HIPEC (colorectal carcinoma, appendix carcinoma, carcinoma of the small intestine, gastric cancer, recurrent ovarian cancer, pseudomyxoma peritonei, primary peritoneal carcinomatosis $^{\mathrm{a}}$ )

- Karnofsky index $>70 \%$

Exclusion criteria:

- Extraabdominal tumor

- Compromised liver kidney or bone marrow function

PCI = Peritoneal cancer index. ${ }^{\text {a }}$ Adenocarcinoma of the ovary with primary extraovarian manifestation.

\section{Interventions}

For cytoreductive surgery, partial or total peritonectomy was performed as necessary and intraabdominal organs were resected depending on tumor dissemination. Hyperthermic chemoperfusion was performed for $60 \mathrm{~min}$ with the inflow temperature set to $41^{\circ} \mathrm{C}$ using the open 'coliseum' technique [14] during this study. We used Mitomycin C and Cisplatin as chemotherapeutic agents, adding oxaliplatin in gastric cancer and docetaxel in ovarian cancer.

\section{Measurements}

Quality of life was assessed preoperatively, 3 months, 9 months, and 18 months postoperatively using the EORTC QLQ-C30 questionnaire [15]. Patients completed a paper-based version of the questionnaire, either alone or with the aid of an examiner. Patients were told that no right or wrong answers exist and that they should respond spontaneously. The QLQ-C30 contains 30 questions, 28 of which allow 4 different answers, while the last two questions are answered using an analogue scale ranging from 1 to 7 . At the time of analysis, these questions are grouped using a predefined formula resulting in 1 scale for global health status, 5 functional scales, 6 symptom scales, and 3 single items. Data were transformed into a scale from 0 to 100 as described in the Scoring Manual, 3rd edition [16]. A high score on a functional scale or for general health status corresponds to good function or quality of life. In symptom scales and single items, a high score corresponds to more severe symptoms or problems in life.

\section{Statistical Analysis}

Patients that completed at least 2 questionnaires (preoperative and 3 months postoperative) entered statistical analysis. In 5 patients, data were available until 18 months of follow-up. The SPSS software (version 17.0) was used for statistical analysis.

Student's t test for paired samples was used to test for differences between preoperative and postoperative measurements. For general health status, we performed an analysis of variance for repeated measurements to confirm changes in quality of life over time. In a subgroup analysis, the $t$ test for unpaired samples was used to test for differences between sexes and between patients with high or low Peritoneal Cancer Index scores at the time of sur- 
Table 2. Quality-of-life measurements and subgroup analysis

\begin{tabular}{|c|c|c|c|c|}
\hline & \multicolumn{4}{|l|}{ Quality of life } \\
\hline & pre-operative & 3 months & 9 months & 18 months \\
\hline All patients & $\begin{array}{l}59(46-72) \\
\mathrm{n}=24\end{array}$ & $\begin{array}{l}44(37-51) \\
\mathrm{n}=24\end{array}$ & $\begin{array}{l}67(56-78) \\
\mathrm{n}=16\end{array}$ & $\begin{array}{l}70(31-109) \\
\mathrm{n}=5\end{array}$ \\
\hline $\begin{array}{l}\text { Sex } \\
\text { Male }\end{array}$ & $\begin{array}{l}26(11-42) \\
\mathrm{n}=7\end{array}$ & $\begin{array}{l}51(34-68) \\
\mathrm{n}=7\end{array}$ & $\begin{array}{l}72(52-93) \\
\mathrm{n}=6\end{array}$ & $\begin{array}{l}58(-32-149) \\
\mathrm{n}=3\end{array}$ \\
\hline Female & $\begin{array}{l}73(61-84) \\
\mathrm{n}=17 \\
\mathrm{p}<0.001\end{array}$ & $\begin{array}{l}42(33-50) \\
n=17 \\
p=0.23\end{array}$ & $\begin{array}{l}64(48-80) \\
n=10 \\
p=0.48\end{array}$ & $\begin{array}{l}88(-71-246) \\
\mathrm{n}=2 \\
\mathrm{p}=0.38\end{array}$ \\
\hline $\begin{array}{l}\text { Tumor type } \\
\text { Colorectal carcinoma }\end{array}$ & $\begin{array}{l}69(44-94) \\
\mathrm{n}=7\end{array}$ & $\begin{array}{l}44(28-61) \\
\mathrm{n}=7\end{array}$ & $\begin{array}{l}77(58-95) \\
\mathrm{n}=5\end{array}$ & $\begin{array}{l}54(-211-319) \\
\mathrm{n}=2\end{array}$ \\
\hline Gastric carcinoma & $\begin{array}{l}40(12-69) \\
\mathrm{n}=6\end{array}$ & $\begin{array}{l}47(34-60) \\
\mathrm{n}=6\end{array}$ & $\begin{array}{l}67(12-121) \\
\mathrm{n}=3\end{array}$ & $\begin{array}{l}71(-300-441) \\
\mathrm{n}=2\end{array}$ \\
\hline Ovarian carcinoma & $\begin{array}{l}83(63-104) \\
n=5\end{array}$ & $\begin{array}{l}32(5-58) \\
\mathrm{n}=5\end{array}$ & $\begin{array}{l}52(1-103) \\
\mathrm{n}=4\end{array}$ & $\begin{array}{l}100 \\
n=1\end{array}$ \\
\hline Pseudomyxoma peritonei & $\begin{array}{l}38(6-71) \\
n=5\end{array}$ & $\begin{array}{l}53(32-75) \\
\mathrm{n}=5\end{array}$ & $\begin{array}{l}72(48-96) \\
\mathrm{n}=3\end{array}$ & \\
\hline Primary peritoneal mesothelioma & $\begin{array}{l}83 \\
n=1 \\
p=0.014\end{array}$ & $\begin{array}{l}50 \\
n=1 \\
p=0.27\end{array}$ & $\begin{array}{l}67 \\
n=1 \\
p=0.42\end{array}$ & $\mathrm{p}=0.41$ \\
\hline $\begin{array}{l}\text { Peritoneal cancer index } \\
\mathrm{PCI} \leq 20\end{array}$ & $\begin{array}{l}60(45-74) \\
\mathrm{n}=19\end{array}$ & $\begin{array}{l}45(37-54) \\
\mathrm{n}=19\end{array}$ & $\begin{array}{l}65(50-79) \\
\mathrm{n}=12\end{array}$ & $\begin{array}{l}63(13-112) \\
\mathrm{n}=4\end{array}$ \\
\hline PCI $>20$ & $\begin{array}{l}57(18-95) \\
\mathrm{n}=5 \\
\mathrm{p}=0.85\end{array}$ & $\begin{array}{l}42(20-64) \\
n=5 \\
p=0.70\end{array}$ & $\begin{array}{l}75(60-90) \\
\mathrm{n}=4 \\
\mathrm{p}=0.48\end{array}$ & $\begin{array}{l}100 \\
\mathrm{n}=1\end{array}$ \\
\hline
\end{tabular}

Data are presented as means and 95\% confidence intervals. PCI = Peritoneal Cancer Index.

gical exploration. We employed one-way analysis of variance to test for differences between tumor entities. A general linear model was used to confirm the results of subgroup analysis. A probability value of $\mathrm{p}<0.05$ was deemed significant for all statistical tests.

\section{Results}

\section{Patient Characteristics}

During the study period, 52 patients presented to our department for peritoneal carcinomatosis. Cytoreduction and HIPEC were performed in 40 of these patients after completion of preoperative workup. In 7 patients, 3-months follow-up was not completed. Therefore, data from 33 patients entered statistical analysis. There were $26(65 \%)$ females and 14 males in this study. The young- est patient was aged 35 , the oldest 70 years, the mean age being 52 (53 years for men and 51 years for women, n.s.). Patients included in this study suffered from five different types of primary tumors (table 2).

\section{Primary Outcome: Quality of Life}

Complete questionnaires were available for analysis from 26 patients 3 months postoperatively. At 9 months, 19 questionnaires were available and at 18 months, 7 questionnaires.

\section{Global Health Status}

Global health status was not influenced significantly by cytoreduction and HIPEC (fig. 1a). A nonsignificant reduction was observed 3 months postoperatively with scores returning to preoperative values within 9 months 


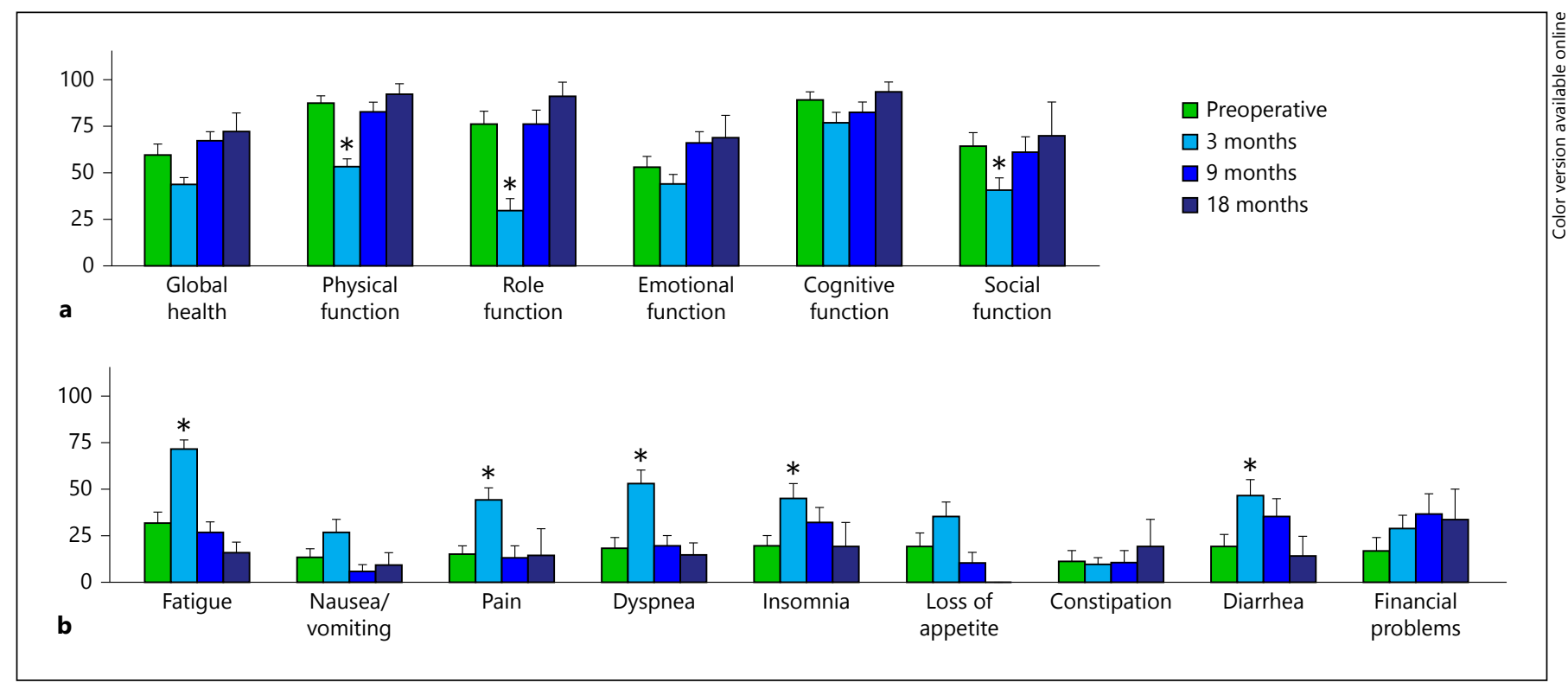

Fig. 1. Quality of life assessment using the EORTC QLQ-C30 questionnaire. The graph shows the results for global health status and functional scales (a) as well as symptom scales and single items (b). For some scales and symptoms, a significant deterioration was observed 3 months postoperatively. On all scales and symptoms,

and staying on this level at 18 months. Analysis of variance for patients that completed 18 months of follow-up confirmed that a significant recovery occurred between 3 months and 9 months postoperatively $(\mathrm{p}=0.009)$, while postoperative scores were not lower than preoperative measurements.

\section{Functional Scales}

Physical function $(\mathrm{p}<0.001)$, role function $(\mathrm{p}<0.001)$, and social function $(\mathrm{p}=0.007)$ scores were reduced 3 months postoperatively but recovered to preoperative scores at 9 months with equal scores at 18 months of follow up (fig. 1a). Emotional and cognitive functions were not altered significantly following cytoreduction and HIPEC but showed a similar pattern.

\section{Symptom Scales and Single Items}

Nausea and vomiting were not severe in our patients and there were no significant postoperative differences (fig. 1b). Fatigue ( $\mathrm{p}<0.001)$, pain $(\mathrm{p}<0.001)$, dyspnea $(\mathrm{p}=0.001)$, insomnia $(\mathrm{p}=0.004)$, and diarrhea $(\mathrm{p}=$ 0.015 ) were more frequent at 3 months compared to preoperative values but not 9 or 18 months. Appetite and the condition of constipation did not change postoperatively.

Quality of Life Following Cytoreductive Surgery and HIPEC however, patients recovered to preoperative levels within 9 months postoperatively. At 18 months, scores obtained were equal or better than at 9 months. Columns show mean values and standard errors. ${ }^{*} \mathrm{p}<0.05$.

\section{Subgroup Analysis}

Tumor Type. For general quality of life, no significant differences were observed between patients with different tumor types at 3 months follow-up. Patients with gastric cancer and pseudomyxoma peritonei had significantly lower preoperative scores $(\mathrm{p}=0.019)$ than other tumor types and they showed no postoperative drop in quality of life. Recovery from 3 to 9 months was similar for all tumor types except for recurrent ovarian cancer patients who recovered more slowly (table 2).

Sex. Changes at 3 months follow-up were calculated separately for male and female patients and tested for differences between the sexes. Significant differences were found only for general health $(\mathrm{p}=0.003)$ and emotional function ( $p=0.008$ ). For both items, these differences were due to a loss of function in female patients and simultaneous improvement in males. In addition, pre- and postoperative scores were compared between male and female patients. Women obtained higher preoperative scores for both general health and emotional function. At 3 months followup, men improved significantly, reaching scores comparable or even better than those of female patients (table 2).

$P C I$. No postoperative differences between patients with PCI $>20$ compared to patients with PCI $\leq 20$ were found (table 2). 
Table 3. Weight development in male and female patients, $\mathrm{kg}(\%)$

\begin{tabular}{llll}
\hline & Male & Female & Range \\
\hline Preoperative weight & 82.6 & 72.5 & $52-110$ \\
Lowest weight & $64.2(-22)$ & $58.8(-19)$ & $42-92$ \\
Last weight & $68.4(-17)$ & $61.8(-15)$ & $46-99$ \\
\hline
\end{tabular}

General Linear Model. To further distinguish influencing factors, an analysis of covariance for general quality of life at 9 months $(\mathrm{n}=16)$ with sex, tumor type, and PCI at surgical exploration as factors and preoperative as well as 3 months postoperative quality of life as covariates was performed. While long-term quality of life in this model was significantly correlated withquality of life at three months ( $p=0.013$ ), it did not depend on sex, tumor type, PCI, or preoperative quality of life.

\section{Postoperative Morbidity}

Complications occurred in 14 patients (35\%). Most frequent were ileus (4 patients), intestinal fistula/perforation, or anastomotic leakage, wound healing disorders and ostomy complications (3 patients each).

\section{Survival and Tumor Recurrence}

Survival analysis included 32 patients. During the observation period, 7 patients $(22 \%)$ died. Five patients (16\%) died of tumor recurrence, one died of postoperative pneumonia, and one patient died of unknown cause.

At the end of the observation period, 15 patients (45\%) had experienced tumor recurrence; 18 patients $(55 \%)$ were disease-free.

\section{Weight Loss}

For all patients, their preoperative body weight, lowest weight during the period of observation, and weight at 18 months follow-up were documented. All patients lost weight following cytoreduction and HIPEC. Most patients gained weight until the termination of this study, some weighing more than before the operation (table 3 ).

\section{Discussion}

This study was designed to determine the impact of cytoreduction and HIPEC on health-related quality of life of patients with peritoneal carcinomatosis from different primary tumors. We used the EORTC QLQ-C30 questionnaire that has been extensively validated to assess the quality of life in tumor patients [15] and is currently the preferred tool in Europe [17]. Only the core questionnaire excluding tumor-specific sub-questionnaires was employed because peritoneal carcinomatosis was caused by different primary tumor entities in our patients. The score descriptively analyses symptoms, but does not allow for conclusions on the underlying causes. Fatigue, for example, may be caused by (preexisting) mental depression or by the operation itself. Early postoperative quality of life was measured at 3 months to document symptoms caused by the surgical procedure. The latest evaluation at 18 months was chosen to extend the observation time span beyond previous studies by other groups that ended at 12 months $[11,18]$.

Before the decision for HIPEC was made, all patients were staged according to the same standards using modern multi-slice CT scanners. Distant metastases were excluded and a Peritoneal Cancer Index (PCI) Score was calculated. Nonetheless, preoperative CT did not always correctly assess the extent of peritoneal carcinomatosis. The limited prognostic value of computed tomography for peritoneal carcinomatosis has been described previously [19]. Intraoperative exploration revealed a PCI $>20$ in nine of our patients, but the surgeon judged the procedure to be technically feasible and HIPEC was successfully performed in all of these patients.

Global health status was not impaired significantly 3 months after surgery or at 9 months; some patients viewed their health to be even better than what it was before surgery. Scales and symptom scores that yielded a significant deterioration 3 months after surgery, that is, physical function, role function, social function, fatigue, pain, dyspnea, insomnia, and diarrhea, all returned to preoperative values within 9 months. At 9 months postoperatively, $80 \%$ of patients were pain-free. For global health, role function, emotional function, fatigue, and appetite, there even appeared to be a tendency toward improved scores in comparison to preoperative values, but our study was not powered to verify these differences. Although some survivorship bias must be assumed, these results justify the conclusion that cytoreductive surgery and HIPEC can be performed without negative long-term impact on the quality of life of surviving patients.

Good or acceptable quality of life had been suggested by previous studies $[10,11,20]$, but their interpretation was limited by the fact that data had been collected retrospectively. Hill et al., in their prospective analysis of patients with peritoneal carcinomatosis of colonic origin, found a pattern of recovery similar to our patients with the exception of emotional function, which was signifi- 
cantly improved in their study not including ovarian cancer patients [18].

Interestingly, female patients in the present study reached lower postoperative scores for emotional function and general health status. Given the descriptive nature of the quality-of-life testing, no conclusions can be drawn as to any causal connection between the two. Nevertheless, the present study suggests that women find it harder to cope with cytoreductive surgery and HIPEC, while recurrence rates did not differ between the two sexes $(\mathrm{p}=0.39$, $\chi^{2}$ test). The unfavorable development in female patients to some extent may have been due to the inclusion of patients with ovarian cancer who suffered from a second recurrence with disease progression under chemotherapy: while patients with other primary tumors, at 9 months after the operation, reached quality-of-life scores 27 points higher than their preoperative values, ovarian cancer patients' score deteriorated by 16 points $(\mathrm{p}=0.045)$.

Interestingly, our general linear model showed that while significant preoperative differences in quality of life between patients with various primary tumors may exist, postoperative quality of life did not depend on tumor entity and recovery was comparable for patients with all types of primary tumor (except ovarian cancer). The analysis of covariance was limited by the relatively small number of cases in this study and high morbidity, which precluded an analysis of the quality of life at 18 months.

Short-term quality of life, which reflects postoperative morbidity, had a more significant impact on long-term quality of life than any other factor analyzed. In this respect, with postoperative quality of life being also independent from the preoperative status, it can be concluded that the decision to offer HIPEC to a patient should be based only on the oncological prognosis and surgical considerations but not on other factors such as sex or preoperative quality of life.

A recent prospective study by Tsilimparis et al. [21] showed a recovery of health-related quality of life similar to our data. This growing evidence from an increasing number of centers indicates that in this highly specialized field of oncological surgery, good results can be achieved not only in a few leading centers that may be operating in extremely favorable conditions but also in many different institutions and healthcare systems.

For a more complete interpretation, these results should be compared to other aggressive surgical therapies. Schniewind et al., for example, found patients' quality of life to be impaired for 3-6 months after pancreaticoduodenectomy for pancreatic cancer with recovery to preoperative levels within 12-24 months [22]. This resembles the time course of recovery observed in the present study, suggesting that cytoreduction and HIPEC do not impair quality of life more than pancreaticoduodenectomy.

It must be emphasized that most patients received adjuvant chemotherapy, which may have caused some of their symptoms, such as lack of appetite, nausea, and vomiting [23]. Patients not receiving chemotherapy had better appetite and less nausea and vomiting (data not shown), which suggests that the contribution of cytoreduction and HIPEC to these symptoms may have been overestimated in the past.

Survival analysis was limited by the relatively short study length, which resulted in varying observation periods for our patients with a maximum of 35 months. With a $22 \%$ mortality rate and only 19 questionnaires from 28 surviving patients available over a period of 9 months, selection bias favoring healthier patients must be assumed and conclusions from our study should be drawn cautiously.

Overall morbidity in the present study was 35\%, which compares well to data published by other groups [6-9]. It must be mentioned, however, that in these earlier studies, the HIPEC procedure and its indications were still being evaluated, resulting in increased morbidity and toxicity.

Almost all patients lost weight in the early postoperative period but regained at least some of it until the end of the observation period. The loss of weight observed in the present study (females: $15 \%$, males: $17 \%$ ) was somewhat more pronounced when compared, for instance, to Whipple's operation [24], colectomy, or partial resection of the small intestine but did not significantly impair quality of life.

\section{Conclusion}

In most patients, quality of life recovered to preoperative levels or higher within 9 months after cytoreduction and HIPEC with very good long-term results at 18 months. Postoperative quality of life did not depend on sex, primary tumor site, or preoperative quality of life. Results are comparable to other types of large abdominal surgery, such as Whipple's operation. Pain was relatively mild and vegetative disorders could to a large extent be attributed to chemotherapy. Selected patients that are likely to benefit oncologically from cytoreduction and HIPEC should not be denied this option for fear of reduced postoperative quality of life.

\section{Disclosure Statement}

The authors have no conflict of interest to declare. 


\section{References}

$\checkmark 1$ Sadeghi B, Arvieux C, Glehen O, Beaujard AC, Rivoire M, Baulieux J, Fontaumard E, Brachet A, Caillot JL, Faure JL, Porcheron J, Peix JL, Francois Y, Vignal J, Gilly FN: Peritoneal carcinomatosis from non-gynecologic malignancies: results of the EVOCAPE 1 multicentric prospective study. Cancer 2000;88:358-363.

2 Carraro PG, Segala M, Cesana BM, Tiberio G: Obstructing colonic cancer: failure and survival patterns over a ten-year follow-up after one-stage curative surgery. Dis Colon Rectum 2001;44:243-250.

- 3 Verwaal VJ, van Ruth S, de Bree E, van Sloothen GW, van Tinteren H, Boot H, Zoetmulder FA: Randomized trial of cytoreduction and hyperthermic intraperitoneal chemotherapy versus systemic chemotherapy and palliative surgery in patients with peritoneal carcinomatosis of colorectal cancer. J Clin Oncol 2003;21:3737-3743.

-4 Verwaal VJ, Bruin S, Boot H, van Slooten G, van Tinteren $\mathrm{H}$ : 8-year follow-up of randomized trial: cytoreduction and hyperthermic intraperitoneal chemotherapy versus systemic chemotherapy in patients with peritoneal carcinomatosis of colorectal cancer. Ann Surg Oncol 2008; 15:2426-2432.

5 Dedrick RL, Myers CE, Bungay PM, DeVita VT Jr: Pharmacokinetic rationale for peritoneal drug administration in the treatment of ovarian cancer. Cancer Treat Rep 1978;62:1-11.

6 Elias D, Blot F, El Otmany A, Antoun S, Lasser P, Boige V, Rougier P, Ducreux M: Curative treatment of peritoneal carcinomatosis arising from colorectal cancer by complete resection and intraperitoneal chemotherapy. Cancer 2001;92:71-76.

7 Jess P, Iversen LH, Nielsen MB, Hansen F, Laurberg S, Rasmussen PC: Quality of life after cytoreductive surgery plus early intraperitoneal postoperative chemotherapy for pseudomyxoma peritonei: a prospective study. Dis Colon Rectum 2008;51:868-874.

$\rightarrow 8$ Levine EA, Stewart JH 4th, Russell GB, Geisinger KR, Loggie BL, Shen P: Cytoreductive surgery and intraperitoneal hyperthermic chemotherapy for peritoneal surface malignancy: experience with 501 procedures. J Am Coll Surg 2007;204:943-953; discussion 953-955.
-9 Piso P, Bektas H, Werner U, Schlitt HJ, Kubicka S, Bornscheuer A, Manns M, Klempnauer J: Improved prognosis following peritonectomy procedures and hyperthermic intraperitoneal chemotherapy for peritoneal carcinomatosis from appendiceal carcinoma. Eur J Surg Oncol 2001;27:286-290.

10 Schmidt U, Dahlke MH, Klempnauer J, Schlitt HJ, Piso P: Perioperative morbidity and quality of life in long-term survivors following cytoreductive surgery and hyperthermic intraperitoneal chemotherapy. Eur J Surg Oncol 2005;31:53-58.

11 McQuellon RP, Loggie BW, Lehman AB, Russell GB, Fleming RA, Shen P, Levine EA: Long-term survivorship and quality of life after cytoreductive surgery plus intraperitoneal hyperthermic chemotherapy for peritoneal carcinomatosis. Ann Surg Oncol 2003;10: 155-162.

12 Glockzin G, Schlitt HJ, Piso P: Peritoneal carcinomatosis: patients selection, perioperative complications and quality of life related to cytoreductive surgery and hyperthermic intraperitoneal chemotherapy. World J Surg Oncol 2009;7:5.

$\checkmark 13$ Jacquet P, Sugarbaker PH: Clinical research methodologies in diagnosis and staging of $\mathrm{pa}$ tients with peritoneal carcinomatosis. Cancer Treat Res 1996;82:359-374.

-14 Stuart OA, Stephens AD, Welch L, Sugarbaker PH: Safety monitoring of the coliseum technique for heated intraoperative intraperitoneal chemotherapy with mitomycin C. Ann Surg Oncol 2002;9:186-191.

-15 Fayers PM: Interpreting quality of life data: population-based reference data for the EORTC QLQ-C30. Eur J Cancer 2001;37: 1331-1334.

16 Fayers PM, Aaronson NK, Bjordal K, Groenvold M, Curran D, Bottomley A; EORTC Quality of Life Group: EORTC QLQ-C30 scoring manual, ed 3. Brussels, European Organisation for Research and Treatment of Cancer, 2001.
17 Fayers P, Bottomley A; EORTC Quality of Life Group, Quality of Life Unit: Quality of life research within the EORTC-the EORTC QLQ-C30. European Organisation for Research and Treatment of Cancer. Eur J Cancer 2002;38(suppl 4):S125-S133.

18 Hill AR, McQuellon RP, Russell GB, Shen P, Stewart JH 4th, Levine EA: Survival and quality of life following cytoreductive surgery plus hyperthermic intraperitoneal chemotherapy for peritoneal carcinomatosis of colonic origin. Ann Surg Oncol 2011;18:36733679.

19 de Bree E, Koops W, Kröger R, van Ruth S, Verwaal VJ, Zoetmulder FA: Preoperative computed tomography and selection of patients with colorectal peritoneal carcinomatosis for cytoreductive surgery and hyperthermic intraperitoneal chemotherapy. Eur J Surg Oncol 2006;32:65-71.

20 Piso P, Glockzin G, von Breitenbuch P, Popp FC, Dahlke MH, Schlitt HJ, Nissan A: Quality of life after cytoreductive surgery and hyperthermic intraperitoneal chemotherapy for peritoneal surface malignancies. J Surg Oncol 2009;100:317-320.

-21 Tsilimparis N, Bockelmann C, Raue W, Menenakos C, Perez S, Rau B, Hartmann J: Quality of life in patients after cytoreductive surgery and hyperthermic intraperitoneal chemotherapy: is it worth the risk? Ann Surg Oncol 2013;20:226-232.

22 Schniewind B, Bestmann B, Henne-Bruns D, Faendrich F, Kremer B, Kuechler T: Quality of life after pancreaticoduodenectomy for ductal adenocarcinoma of the pancreatic head. Br J Surg 2006;93:1099-1107.

23 Warr DG: Chemotherapy-and cancer-related nausea and vomiting. Curr Oncol 2008; 15 : S4-S9.

24 Tran KT, Smeenk HG, van Eijck CH, Kazemier G, Hop WC, Greve JW, Terpstra OT, Zijlstra JA, Klinkert P, Jeekel H: Pylorus preserving pancreaticoduodenectomy versus standard Whipple procedure: a prospective, randomized, multicenter analysis of $170 \mathrm{pa}$ tients with pancreatic and periampullary tumors. Ann Surg 2004;240:738-745. 